\title{
Monitoring of Myocardial Energy Metabolism as an Early Marker of Life Threatening Conditions
}

\author{
DOI: 10.17691/stm2017.9.1.19
}

Received August 27, 2015

O.V. Krasnikova, PhD, Associate Professor, Department of General Chemistry';

I.A. Petrova, Researcher, Hygiene Department2;

S.V. Nemirova, MD, PhD, Associate Professor, Department of Hospital Surgery named after B.A. Korolev';

A.P. Medvedev, MD, DSc, Professor, Head of the Department of Hospital Surgery named after B.A. Korolev1;

B.E. Shakhov, MD, DSc, Professor, Head of the Department of Radiodiagnosis,

Faculty of Doctors' Advanced Training, Rector ${ }^{1}$;

A.S. Gordetsov, MD, DSc, Professor, Head of the Department of General Chemistry ${ }^{1}$

${ }^{1}$ Nizhny Novgorod State Medical Academy, 10/1 Minin and Pozharsky Square, Nizhny Novgorod, 603005, Russian Federation;

${ }^{2}$ Nizhny Novgorod Research Institute of Hygiene and Occupational Pathologies, 20 Semashko St.,

Nizhny Novgorod, 603950, Russian Federation

The aim of the investigations was to verify early signs of heart failure decompensation and its progression in cardiosurgical patients according to the dynamics of myocardial energy metabolism indices.

Materials and Methods. We examined 80 cardiosurgical patients, who had undergone artificial circulation surgeries in Nizhny Novgorod Specialized Cardiac Surgery Clinical Hospital. A control group consisted of 40 healthy volunteers. The concentration of glucose and high-energy compounds was determined by infrared spectroscopy of blood serum in the absorption band 1,200-1,000 cm-1, typical for phosphorus-containing compounds and glucose. To verify the concentration dynamics of fatty acids, gas chromatography was used.

Results. The study revealed the regularity of occurrence of life threatening conditions caused by changed direction of myocardial energy metabolism: the accumulation of glucose and fatty acids in blood serum due to reduced glycolysis rate and intensity, and lipolysis caused by myocardial oxygen deprivation and accompanying concentration change of high-energy compounds.

Conclusion. In heart failure decompensation and tissue hypoxia in myocardial cells there is the decrease of glycolysis and lipolysis rate resulting in an increased concentration of glucose and fatty acids against a decreased concentration of adenosine triphosphoric acid that still aggravates myocardial dysfunction and ischemia. The changes can serve as the early markers of life threatening conditions.

Key words: myocardial energy metabolism; heart failure; infrared spectroscopy; gas chromatography.

Acute heart failure including acute decompensation of cardiac failure is a life threatening condition requiring an early diagnosis and immediate treatment [1-3]. In recent years, great importance is given to the study of capabilities of prognosis and progression prevention of the disease, which is due to acute myocardial damage, as a rule. It is the decompensation periods, when the myocardium is damaged, that are of serious hazard to a patient's life, since the course of the disease changing dramatically raising the risk of fatality [4].

The problem is the most urgent for cardiosurgical patients, who can develop the postoperative decompression of heart failure that level a positive effect of high-technology, labor-intensive surgeries. Therefore, the most significant things are to determine a surgical risk and the disease prognosis in a postoperative period, as well as the search of possible ways to reduce the postoperative complication rate, and it is the reveal of universal markers of cardiac failure that will enable to detect the negative trend and escape the development of irreversible changes regardless the underlying disease and accompanying pathology.

Numerous studies of heart failure etiology and pathogenesis enabled to estimate the crucial significance of myocardial energy metabolism changes in the condition development. Currently, there are three main theories of myocardial energy metabolism changes resulting in myocardial metabolism impairments: cardiorenal, cardio-circulatory and neurohumoral [5], however, there is no agreement of opinion on the problem. On the other hand, needless to say fatty acids is the basic energy substrate of a cardiomyocyte under normoxia, as they provide up to $60 \%$ of adenosine triphosphate synthesis in a cardiomyocyte, while the oxidation of lactate, glucose, and other substrates provides only up to $40 \%$ of myocardial energy requirements [6].

Creatinine phosphate and adenosine triphosphate synthesis are known to decrease in ischemia resulting

For contacts: Olga V. Krasnikova, e-mail: lala-g@yandex.ru 
in anaerobic glycolysis activation. Moreover, lactic acid and only two molecules of adenosine triphosphoric acid are synthesized from pyruvate that cannot provide adequate energy requirements of the myocardium. Lactate synthesized in excess is not just released from a cell that is a reliable sign of myocardial ischemia but also accumulates in cytosol resulting in intracellular acidosis and further cardiomyocyte dysfunction [7].

Adenosine triphosphate hydrolysis causes the formation of adenosine monophosphate, which against acidosis activates kinase suppressing acetyl coenzyme A carboxylase leading to the decreased synthesis of malonyl-coenzyme $\mathrm{A}$, and as a consequence, the increase in carnitine palmitoyltransferase 1 activity. As a result, mitochondria capture a large number of fatty acids, and more acetyl coenzyme $A$ is formed that inhibits pyruvate dehydrogenase and disconnects pyruvate glycolysis and oxidation. Cardiomyocyte metabolism is switched to the oxidation of fatty acids [8].

When free fatty acids are used as energy substrate, the efficiency of myocardial energy supply is 30\% higher than in case glucose is used. However, free fatty acids utilization is known to be related to a higher oxygen uptake that is wasteful for cardiomyocyte in ischemia. If glucose is used as an energy substrate, the amount of adenosine triphosphoric acid formed per $1 \mathrm{~mol}$ of absorbed oxygen is $15 \%$ higher than in free fatty acids utilization $[6,9,10]$. Thus, "oxygen cost" of an adenosine triphosphate molecule formed in glucose utilization is lower than that formed in free fatty acids oxidation. Therefore, since the increased utilization of fatty acids to provide the myocardial function results in an increased oxygen uptake, the process serves as the most effective way of energy production under normal myocardial oxygenation, while under myocardial ischemia, the most preferable way is glucose oxygenation, since this way is less dependent on oxygen concentration $[6,7,11]$.

Moreover, under oxygen deficiency, in a cell underoxidized fatty acids accumulate that further disconnects tissue respiration and contribute to malfunction of cell membranes. The increase in fatty acids leads to the change of ionic pump functioning, sodium and calcium excess in a cell that breaks the capability of cardiomyocytes to relax and contract. In this situation, the necessity for using residual adenosine triphosphate to maintain transmembrane ion gradients aggravates the contractile dysfunction of cardiomyocytes [6-8].

Impaired glucose tolerance is proved to have preceded acute heart failure in $29 \%$ patients, and type 2 diabetes is firstly diagnosed in $21 \%$ patients with cardiac decompensation. Moreover, the patients with acute myocardial infarction were revealed to have significant direct correlation between cardiac failure frequency and fasting glucose [12].

Thus, initial hyperglycemia is known to provoke heart failure development and progression; however, there have been no studies on the importance of the secondary blood sugar level increase and impaired lipid metabolism against the primarily existing and progressive heart failure and in its decompensation, which is particularly acute in an early postoperative period in cardiosurgical patients.

The aim of the investigations was to verify early signs of heart failure decompensation and its progression in cardiosurgical patients according to the dynamics of myocardial energy metabolism indices.

Materials and Methods. The clinical laboratory study involved 120 patients, the work being performed in two stages. The first stage revealed normal infrared (IR) spectrum of the blood components, which are the most informative for heart failure (group 1 patients), the second stage revealed the dynamics of IR spectroscopy findings in cardiac decompensation (group 2 patients).

Group 1 (control group) consisted of the volunteers with no cardiac failure signs $(n=40)$, and group 2 (study group) included 80 cardiosurgical patients, who had undergone artificial circulation surgeries in Nizhny Novgorod Specialized Cardiac Surgery Clinical Hospital. Patients' mean age was $57.21 \pm 4.38$ years (from 29 to 68 years). Regardless the disease (coronary heart disease, pulmonary and right heart embolism, valvular heart disease) and its etiology, group 2 patients were divided into three subgroups:

subgroup $2 \mathrm{~A}$ involved the patients, who clinically had had no severe heart failure in an early postoperative period according to laboratory and instrumental findings $(\mathrm{n}=50)$;

subgroup 2B involved the patients with evident signs of decompensation and heart failure augmentation in an early postoperative period with the following positive answer to intensive care $(n=20)$;

subgroup $2 \mathrm{C}$ included the patients with evident decompensation signs and heart failure augmentation resulted in lethality on day $3(n=10)$.

The study was carried out in accordance with the declaration of Helsinki (adopted in June 1964, Helsinki, Finland and revised in October 2000, Edinburg, Scotland) and was approved by the Ethics Committee of Nizhny Novgorod State Medical Academy. All patients gave their written informed consent.

Blood samples $(5.0 \mathrm{ml})$ were taken from cubital vein in group 2 patients in the morning, on the eve of the surgery, as well as during a postoperative period on days $1-10$; in group 1 at the same time and the same blood sample volume was taken. The blood was centrifuged, $1,000 \mathrm{rpm}$ for $15 \mathrm{~min}$. The separated serum $(1.0 \mathrm{ml})$ was dried in a hot-air sterilizer in Petri dish at $25^{\circ} \mathrm{C}$ within $24 \mathrm{~h}$. The dry serum residue was ground and suspended in liquid paraffin.

IR spectra of dried blood serum were obtained on spectrophotometers SPECORD IR-75 and M80 (Carl Zeiss Jena, Germany), photometric error being $0.2 \%$. We determined the peak height of absorption bands, max $1,165 \mathrm{~cm}^{-1}$ corresponding to IR spectra of nucleoside triphosphate, and $1,005 \mathrm{~cm}^{-1}$ corresponding to glucose 
IR spectrum [13]. In addition, we verified the maximum peaks 1,050 and $1,025 \mathrm{~cm}^{-1}$, since our previous studies [14-16] revealed the information significance of the relationship of absorption bands 1,005/1,050 ( $B_{1}-$ glucose) and 1,165/1,025 ( $\left.\mathrm{B}_{2}-\mathrm{ATP}\right)$ for coronary heart disease diagnosis.

To verify the concentration dynamics of fatty acids we used gas chromatography being highly accurate, specific and complementary to IR spectroscopy, which does not enable to differentiate a particular substance from the complex of compounds comprising $\mathrm{CO}$ group.

Methyl ethers of fatty acids were identified by comparing the retention time of methylate standards of higher fatty acids with chromatogram peaks. The data were processed on hardware and software system Chromatec (Russia). HFA were quantitatively assessed by a normalization principle of peak areas of their methylated derivatives.

Higher fatty acids were determined on a gas chromatographic unit Chromos GKh-1000 (Chromos, Russia) equipped by a plasma ionization detector and capillary column with polyethylene glycol phase (ZB FFAP $50 \mathrm{~m} \times 0.32 \mathrm{~m} \times 0.5 \mu \mathrm{m}$; Phenomenex, USA) modified by nitro-terephthalic acid. The applied equipment meets the technical conditions TU 9443-00152470488-2006.

The findings on higher fatty acids and glucose content by the characteristics of blood serum infrared absorption were processed by an application software package Statistica 6.0 and Microsoft Excel using univariate statistics. The findings were presented as $\mathrm{M} \pm \mathrm{m}$, where $M$ is arithmetic mean, and $m$ is standard deviation. The significance of differences of mean values was determined by Student t-test using Bonferroni correction. Paired intra- and intergroup mean values were also compared by Wilcoxon and Mann-Whitney tests. The samplings were considered to belong to different general populations if $p \leqslant 0.05$.

Results and Discussion. To assess the condition of energy metabolism components (higher fatty acids, glucose) in decompensation, and in increase and decrease of marked cardiac failure, we studied IR spectral blood serum profile in cardiosurgical patients that enabled to reveal at a single-step the most significant changes of a wide range of compounds.

The findings of the relations of absorption peaks, glucose content, the concentration of fatty acids: saturated fatty acids (SFA), monounsaturated fatty acids (MUSFA), arachidonic acid (AA) in blood serum of group 1 and group 2 patients in pre- and postoperative periods (See the Table) show that all group 2 patients before surgery had a significant initial increase in glucose content in blood by $45.5 \%$ when ATP concentration concurrently decreased by $67.7 \%$ compared to the norm $(p \leqslant 0.001)$.

The obtained IR data correlate with standard biochemical glucose assays $(r=1.0)$.

In blood of all the patients on the first postoperative day glucose content was significantly higher compared to the initial data: on average, by $36.4 \% \quad(p \leqslant 0.001)$. According to literature data $[17,18]$, in ischemia, glucose oxidation is the preferable way. However, according to our findings, glucose content in patients' blood serum in cardiac decompensation increases.

Thus, it is arguable that on a cell level, myocardial ischemia is characterized just by the decrease of glucose oxidation rate. Therefore, the use of pharmaceutical preparations inducing glucose oxidation should be considered as the most promising direction of myocardial cytoprotection [19]. The work [20] has also demonstrated the inhibition of both oxidation systems in ischemia: both glucose and fatty acids, however, glucose oxidation is inhibited to a greater degree. Therefore, to prevent the decrease in intracellular ATP concentration, glucose oxidation rate should be induced.

The study of SFA, MUSFA, and AA concentrations in blood serum showed the patients with advanced heart failure to have lower SFA content than in group 1 -

The change of carbohydrate and lipid metabolism metabolites in operated cardiosurgical patients (MIm)

\begin{tabular}{|c|c|c|c|c|c|c|}
\hline \multirow{2}{*}{$\begin{array}{l}\text { Patients' groups } \\
\text { and time of blood taking }\end{array}$} & \multicolumn{2}{|c|}{ Relations of absorption band peaks } & \multirow{2}{*}{$\begin{array}{l}\text { Glucose content } \\
\text { (mg/dl) }\end{array}$} & \multicolumn{3}{|c|}{ Concentration of fatty acids (mass $/ \%$ ) } \\
\hline & $P_{1}$ (glucose) & $P_{2}($ ATP $)$ & & SFA & MUSFA & $\mathrm{AA}$ \\
\hline Group 1 & $0.55 \pm 0.15$ & $0.57 \pm 0.11$ & $88 \pm 22$ & $36.54 \pm 2.57$ & $22.57 \pm 1.81$ & $3.69 \pm 0.85$ \\
\hline Group 2 before operation & $0.80 \pm 0.09^{*}$ & $0.34 \pm 0.05^{*}$ & $120 \pm 5^{\star}$ & $34.55 \pm 1.13$ & $28.25 \pm 1.22^{*}$ & $4.22 \pm 0.31$ \\
\hline \multicolumn{7}{|l|}{ Group 2 after operation: } \\
\hline day 1 & $1.28 \pm 0.21^{* v}$ & $0.22 \pm 0.03^{\star v}$ & $195 \pm 50^{* v}$ & $36.56 \pm 0.45^{\vee}$ & $25.64 \pm 1.43^{v}$ & $4.91 \pm 0.32^{v}$ \\
\hline day $3(2 A)$ & $0.89 \pm 0.10^{*+}$ & $0.27 \pm 0.01^{* \mathrm{v}+}$ & $132 \pm 11^{*+}$ & $36.86 \pm 0.34^{v}$ & $29.86 \pm 0.45^{\star+}$ & $4.14 \pm 0.23^{+}$ \\
\hline day $3(2 B, 2 C)$ & $1.04 \pm 0.13^{*}$ & $0.12 \pm 0.03^{\star_{v+}}$ & $140 \pm 11^{*_{\mathrm{v}+}}$ & $31.96 \pm 0.31^{*_{v+}}$ & $20.32 \pm 0.25^{\star_{v+}}$ & $14.59 \pm 3.26^{\star v+}$ \\
\hline day 6 & $0.73 \pm 0.09^{+}$ & $0.27 \pm 0.01^{* \mathrm{v+}}$ & $115 \pm 5^{+}$ & $36.07 \pm 0.23$ & $28.15 \pm 0.56^{\star+}$ & $3.74 \pm 0.11^{+}$ \\
\hline day 9 & $0.63 \pm 0.05^{v+}$ & $0.32 \pm 0.01^{*+}$ & $100 \pm 9^{v+}$ & $36.25 \pm 0.24^{v}$ & $29.11 \pm 0.13^{*+}$ & $3.58 \pm 0.01^{v+}$ \\
\hline
\end{tabular}

N o t e. $P_{1}, P_{2}$ : the relationship of absorption bands $1,005 / 1,050$ and 1,165/1,025; SFA: saturated fatty acids; MUSFA: monounsaturated fatty acids; AA: arachidonic acid; * statistically significant values compared to the healthy volunteers group $(p \leqslant 0.001)$; ${ }^{\vee}$ compared to patients group in a preoperative period $(p \leqslant 0.001) ;{ }^{+}$compared to patients group in first day postoperative period $(p \leqslant 0.001)$. 
by $6 \%$ on average $(p=0.69)$, and higher MUSFA concentration - by $25.1 \%$ on average $(p \leqslant 0.001)$. The findings are consistent with the data [21] demonstrating that in ischemia, lipolysis is energetically unfavorable, since SFA are not spent during oxidation and, therefore, MUSFA content is increasing. In addition, there is AA content increased: by $14.4 \%$ on average $(p=0.71)$, and its metabolites play a key role in platelet aggregation regulation and thrombogenesis. Thus, in ischemia due to heart decompensation, lipolysis and glycolysis rate decreases, i.e. oxidative substrates are not consumed, and ATP content sharply decreases.

The findings are proved by the negative dynamics of the relationship values of absorption band peaks of these patients on the first postoperative day compared to their parameters before the surgery. The Table shows that on the first postoperative day, at the peak of decompensation, there was the significant increase of blood glucose - by $60 \%$ on average at concurrent decrease of ATP concentration - by $55.2 \%$ on average $(p \leqslant 0.001)$.

The analysis of gas chromatography findings in the patients of this group showed the content of fatty acids in blood to have changed in an early postoperative period. The Table demonstrates SFA content in blood of patients with developing heart failure in an early postoperative period to increase by $6 \%$ on day 1 , and AA - by $16.3 \%$, while MUSFA content decreased by $10.2 \%(p \leqslant 0.001)$. MUSFA are likely to be spent on AA synthesis, the metabolites of which are consumed in an early postoperative period.

Our studies demonstrate SFA in an early postoperative period to accumulate in blood plasma of patients, and according to literature data [6,7], under normal oxygen conditions, it is fatty acids that are the main oxidative substrates. High level of glucose and fatty acids suggests lipolysis and glycolysis rates to decrease sharply. Therefore, at this time these patients have energy metabolism imbalance associated with increased heart decompensation.

On day 9 of the postoperative period the patients with advanced heart decompensation (subgroup 2B) had a significant decrease of glucose level in blood serum: by $50 \%$ on average, and concurrent ATP concentration increase - by $44.6 \%$ on average $(p \leqslant 0.001)$ compared to day 1 .

On day 9 of the postoperative period, MUSFA in blood serum of these patients increased by $13.5 \%$ $(p \leqslant 0.001)$ compared to day 1 , while SFA level did not change $(p=0.955)$, and AA concentration decreased by $37.2 \%(p \leqslant 0.001)$. These changes are consistent with clinical and echocardiography presentation with the reduced intensity of the heart failure signs: alleviation of breathlessness, edema, normalized heart rate and arterial pressure, left ventricular ejection fraction increase.

The analysis of gas chromatography findings revealed a gradual decrease of body AA need, and therefore,
MUSFA, which are AA substrate synthesis, are not spent.

The study of the dynamics of glucose, fatty acids and ATP within the first 10 postoperative days in most patients of $2 A$ subgroup - with no signs of heart failure in an early postoperative period - revealed a general tendency to the normalization of energy metabolism values that is consistent with the changed clinical presentation and echocardiography findings.

SFA total level does not change that suggests the following: glucose is still used as the main oxidative substrate for ATP, since in case of successful treatment, the content of glucose, fatty acids, ATP, AA in patient's blood normalize on day $9(p \leqslant 0.001)$. The fact that in a postoperative period, glucose level keeps decreasing, i.e. glucose is used as the main energy source, while the content of fatty acids changes slightly, is inconsistent with literature data [18] demonstrating that in normoxia, primarily, lipolysis occurs.

Based on the findings, it can be expected that fatty acids compared to glucose are the less effective ATP source, since more oxygen is required to produce the same amount of ATP when fatty acids are oxidized. Therefore, to save oxygen, a cardiomyocyte uses glucose as the main oxidative substrate.

Thus, the present study shows that in heart decompensation and tissue hypoxia, in myocardial cells the glycolysis and lipolysis rate decreases resulting in an increased glucose level and fatty acids against ATP decrease that still aggravates the impaired cardiomyocyte function and ischemia. The revealed regularity enables to assess objectively qualitative and quantitative changes of blood serum components in patients with heart failure, and reveal the impairments accompanying the energy metabolism changes in myocardiocytes under progressive heart failure. Moreover, clinicians can screen the condition of myocardial metabolic processes, determine the severity of the metabolic changes at the earliest postoperative period after cardiac artificial circulation surgery by objectifying the prognosis of a postoperative course in cardiosurgical patients, and justifying the choice of an adequate and early correction of the treatment provided.

Conclusion. Energy metabolism indices such as glucose and fatty acids can serve as early markers of cardiomyocyte dysfunction and life threatening conditions.

Study Funding. The study was not funded by any sources.

Conflicts of Interest. The authors have no conflicts of interest related to the present study.

\section{References}

1. Cheng J.W.M., Nayar M. A review of heart failure management in the elderly population. Am $J$ Geriatr Pharmacother 2009; 7(5): 233-249, https://doi.org/10.1016/j. amjopharm.2009.10.001. 
2. Ageev F.T., Arutyunov G.P., Belenkov Yu.N. Khronicheskaya serdechnaya nedostatochnost': rukovodstvo [Chronic heart failure: guidance]. Moscow: GEOTAR-Media; 2010; 336 p.

3. McMurray J.J.J.V. Improving outcomes in heart failure: a personal perspective. Eur Heart J 2015; 36(48): 3467-3470, https://doi.org/10.1093/eurheartj/ehv565.

4. Kositsyna I.V., Tereshchenko S.N., Uskach T.M., Golubev A.V., Nasonova S.N., Zhirov I.V. New opportunities in acute decompensated heart failure treatment. Kardiologicheskiy vestnik 2014; 9(2): 68-74.

5. Ussher J.R., Lopaschuk G.D. Clinical implications of energetic problems in cardiovascular disease. Heart Metab 2006; 32: 9-17.

6. Mann D.L. Mechanisms and models in heart failure: the biomechanical model and beyond. Circulation 2005; 111(21): 2837-2849, https://doi.org/10.1161/ circulationaha.104.500546.

7. Lopaschuk G.D., Ussher J.R., Folmes C.D.L., Jaswal J.S., Stanley W.C. Myocardial fatty acid metabolism in health and disease. Physiol Rev 2010; 90(1): 207-258, https:// doi.org/10.1152/physrev.00015.2009.

8. Ventura-Clapier R., Garnier A., Veksler V. Energy metabolism in heart failure. J Physiol 2004; 555(1): 1-13, https://doi.org/10.1113/jphysiol.2003.055095.

9. Ingwall J.S. Energy metabolism in heart failure and remodelling. Cardiovasc Res 2008; 81(3): 412-419, https://doi. org/10.1093/cvr/cvn301.

10. Shilov A.M., Knyazeva L.V. Capabilities of metabolic medications in ischemic syndrome correction. Lechashchiy vrach 2013; 7: 59 .

11. Shilov A.M., Osiya A.O., Eremina I.V., Cherepanova E.V. Application possibilities of metabolic medications (Trimetazidine) in chronic heart failure management. Russkiy meditsinskiy zhurnal 2010; 25: 1493.

12. Pavlikova E.P. Ostraya serdechnaya nedostatochnost' pri infarkte miokarda: chastota razvitiya, klinicheskaya $i$ gemodinamicheskaya kharakteristiki, faktory, vliyayushchie na techenie i prognoz, sovremennye podkhody k lecheniyu. Dis. ... dokt. med. nauk [Acute heart failure in myocardial infarction: frequency, clinical and hemodynamic characteristics, factors contributing to the course and prognosis, current approaches to treatment. DSc Dissertation]. Moscow; 2009.

13. Norman A. Working atlas of infrared spectroscopy. Boston: SPIE, 1978.

14. Krasnikova O.V. Fiziologicheskiy analiz infrakrasnykh spektrov plazmy krovi zhivotnykh $v$ norme $i$ pri eksperimental'nom onkogeneze. Dis. ... kand. biol. nauk [Physiological analysis of infrared spectra of animals' blood plasma in health and experimental oncogenesis. PhD Thesis]. Nizhny Novgorod; 2012.

15. Gordetsov A.S., Krasnikova O.V., Fedorova M.V., Medvedev A.P., Zimina S.V., Prytkov V.V., Kordatov P.N., Zhurko S.A., Shakhov B.E. Sposob otsenki riska razvitiya neblagopriyatnykh serdechno-sosudistykh sobytiy u patsientov $s$ zabolevaniyami miokarda, podvergshikhsya operatsii $s$ iskusstvennym krovoobrashcheniem [A technique to assess the risk of unfavorable cardiovascular events in patients with myocardiopathies, who underwent surgeries with artificial circulation]. Patent 2504780. 2014.

16. Gordetsov A.S., Krasnikova O.V., Fedorova M.V., Medvedev A.P., Zimina S.V., Prytkov V.V., Kordatov P.N., Zhurko S.A., Shakhov B.E. Sposob diagnostiki zabolevaniya miokarda [Diagnostic technique of myocardiopathy]. Patent 2519097. 2014.

17. Oslopov V.N., Oslopova Yu.V. Coronary heart disease. Angina pectoris. Management. Russkiy meditsinskiy zhurnal 2014; 4: 288-292.

18. Olesova V.M., Markatyuk O.Y., Yurova J.Y., Obrezan A.G. Myocardial metabolism and metabolic drugs. Kardiologiya 2013; 53(1): 66-71.

19. Statsenko M.E., Turkina S.V., Lempert B.A., Evtereva E.D. The use of metabolic drugs in the complex therapy of coronary heart disease. Lechashchiy vrach 2012; 3: 77 .

20. Baranova M.N., Skripchenko A.E., Ogarkov M.Yu., Chavdar F.N. The application of Predizin in coronary heart disease management. Russkiy meditsinskiy zhurnal 2013; 17: 880.

21. Sokolov I.V., Buryachkovskaya E.I., Zykova L.I., Goloborodova A.A. Dynamics of morphological structures of platelets in patients with ischemic heart disease in dependence on blood levels of fatty acids. Kardiologiya 2011; 51(1): 29-33. 